\title{
Attachment force of the beetle Cryptolaemus montrouzieri (Coleoptera, Coccinellidae) on leaflet surfaces of mutants of the pea Pisum sativum (Fabaceae) with regular and reduced wax coverage
}

\author{
Elena Gorb · Dagmar Voigt · Sanford D. Eigenbrode • \\ Stanislav Gorb
}

Received: 1 April 2008/Accepted: 22 October 2008/Published online: 9 November 2008

(C) The Author(s) 2008. This article is published with open access at Springerlink.com

\begin{abstract}
This study represents an investigation of surface-related plant-insect interactions. Surface micromorphology of leaflets in pea (Pisum sativum) with wildtype crystalline surface waxes (waxy) and with reduced crystalline surface waxes (glossy) caused by a mutation (wel) were studied using various microscopy techniques. The free surface energy of these plant surfaces was estimated using contact angles of droplets of three different liquids. The morphological study of the attachment system in the ladybird beetle Cryptolaemus montrouzieri was combined with measurements of attachment (traction) forces, generated by beetles on these plant substrates. Differences were found in wax crystal shape, dimensions, and density between the adaxial and abaxial surfaces of waxy and glossy plants. The crystalline wax was not completely eliminated in the glossy plant: it was only
\end{abstract}

Handling editor: Lars Chittka.

E. Gorb $(\bowtie) \cdot$ D. Voigt

Evolutionary Biomaterials Group, Department of Thin Films and Biological Systems, Max Planck Institute for Metals Research,

Heisenbergstr. 3, 70569 Stuttgart, Germany

e-mail: o.gorb@mf.mpg.de

D. Voigt

e-mail: voigt@mf.mpg.de

S. D. Eigenbrode

Department of Plant, Soil and Entomological Sciences, College of Agricultural and Life Sciences, University of Idaho, Moscow, ID 83844-2339, USA

e-mail: sanforde@uidaho.edu

\section{S. Gorb}

Department of Zoology: Functional Morphology and Biomechanics, Zoological Institute, University of Kiel, Am Botanischen Garten 1-9, 24098 Kiel, Germany

e-mail: s.gorb@mf.mpg.de; sgorb@zoologie.uni-kiel.de slightly reduced on the adaxial side and underwent greater changes on the abaxial side. The free surface energy for both surfaces of both pea types was rather low with strongly predominating dispersion component. Insects generated low traction forces on all intact plant surfaces studied, except the abaxial surface of the glossy plant, on which the force was greater. After being treated with chloroform, all the surfaces allowed much higher traction forces. It is demonstrated that the difference in the crystal length and density of the epicuticular wax coverage within the observed range did not influence wettability of surfaces, but affected insect attachment. The reduction in insect attachment force on plant surfaces, covered with the crystalline wax, is explained by the decrease of the real contact area between setal tips of beetles and the substrate.

Keywords Adhesion - Coccinellidae - Coleoptera . Contact angle - Epicuticular crystalline waxes - Fabaceae . Free surface energy $\cdot$ Mutant $\cdot$ Traction force

\section{Introduction}

Epicuticular waxes, covering primary aerial surfaces in leaves, flowers, fruits and nonwoody stems in terrestrial plants, appear predominantly as a thin smooth amorphous film or layer. Additionally, microscopically small crystals, protruding from the film, cause the pruinosity or powdery appearance of the surface in many plant species (Barthlott et al. 1998). Such pruinose surfaces contribute prominently to the mechanical strength of the tissue, to the protection against harmful radiation, to the limitation of uncontrolled water loss or leaching from interior and foliar uptake, to the control of water status, to the cueing of host-pathogens/ insects recognition and epidermal cell development, to the 
reduction of contamination and pathogen attack, and to the promoting or preventing insect attachment and locomotion (see reviews by Barthlott 1990 and Bargel et al. 2006).

Regarding the latter function, it has been previously repeatedly reported that plant surfaces, bearing crystalline wax coverage, reduce the attachment of insects (Stork 1980, 1986; Edwards 1982; Bodnaryk 1992; Eigenbrode 1996; Eigenbrode and Kabalo 1999; Eigenbrode et al. 2000; Federle et al. 2000; Eigenbrode and Jetter 2002; Gaume et al. 2002, 2004; Gorb and Gorb 2002; Gorb et al. 2005; Voigt et al. 2007). In some of these studies, conducted with different insect and plant species, it has been experimentally shown that insects were able to attach successfully to smooth substrates, without wax or with removed wax, but failed on pruinose surfaces.

Recent studies, carried out with mutants of Pisum sativum L. (Fabaceae), exhibiting essential differences in the wax coverage, confirmed anti-adhesive properties of the wax bloom (Eigenbrode et al. 1998; 2008; Rutledge and Eigenbrode 2003). Mutants with a highly reduced wax coverage demonstrated considerable enhancement of the insect attachment force: a multi-fold (from almost 2 to $>30$ ) force increase on glossy plants compared to waxy ones was measured, depending on the insect species and method of force measurement. Force values obtained in different studies with the same $P$. sativum mutants differed considerably and only the adaxial leaflet surfaces were examined.

The aim of this study was to compare attachment ability of beetles Cryptolaemus montrouzieri Mulsant to different leaflet surfaces in the $P$. sativum with well developed or reduced crystalline wax in order to understand these surface-related plant-insect interactions in further detail. A comprehensive investigation was undertaken to examine the leaflet surfaces, including surface micro-morphology and physicochemical properties, and the morphology of the beetle attachment system, and to use this information to interpret differences in attachment (traction) forces generated by the insects on four plant substrates.

\section{Materials and methods}

\section{Plant and insect species}

The field or garden pea $P$. sativum is an annual herb with pinnately compound leaves, which in leafy types consist of two stipules at the base of the leaf, one or more pairs of opposite, broad and ovate petiolulate leaflets, several pairs of tendrils and a single or compound terminal tendril (Aichele and Schwegler 2000). The plant originated from the Mediterranean area and Middle East (wild genotypes $P$. humile J.I. and P. elatius L., Waines 1975) and is cultivated worldwide mostly as a human and animal food, and as a source of pharmacologicals (Kunkel 1984; Cooper and Johnson 1998; McGuffin et al. 2000).

Two sister lines of $P$. sativum differing in expression of the wax mutation wel (Marx 1969) were developed from accession PI W6-15368 (Marx 406). They differ in the epicuticular wax coverage in both (1) amount of wax material and (2) wax micromorphology and composition, as described by Eigenbrode et al. (1997). The line $406 \mathrm{~N}$ (later called waxy), which is homozygous for the wild-type allele Wel, has a well-developed wax bloom on all photosynthetically active surfaces. The line 406G (later called glossy) is homozygous for wel and shows substantial wax reduction. Both lines are also homozygous for the recessive mutation $t l$ (acacia leaf), which turns all tendrils into leaflets and because of this provides larger surface area for foraging insects compared to standard peas, where some leaflets appear as tendrils (Eigenbrode et al. 2008).

Seeds, treated with the commercial rate of Captan 400 fungicide (Gustafson Ltd., Plano, USA), were sown in small, $9 \mathrm{~cm}$ in diameter, plastic pots ( 3 plants per pot) in a commercial potting soil ASB-Greenworld Premium, NPK: 14-16-18 (ASB-Gruenland Helmut Aurenz GmbH, Lugwigsburg, Germany). Plants were grown in a room greenhouse at $20-25^{\circ} \mathrm{C}, 40-45 \%$ humidity, a $12 \mathrm{~L}: 12 \mathrm{D}$ photoregime and bottom-watered daily. Plants having from 3 to 4 nodes were used in the study.

The Australian ladybird beetle $C$. montrouzieri was chosen as a model insect species for traction experiments because of its commercial availability and appropriate body size (4-5 $\mathrm{mm}$ in length). It originated from Australia and after being imported first to North America, is widely used for biological control against mealy bugs throughout the world (Booth and Pope 1986). Adult beetles were obtained from a commercial supplier (Katz Biotech AG, Welzheim, Germany) and kept in a ventilated cage at $22-24^{\circ} \mathrm{C}, 40-60 \%$ humidity. Insects were fed with a solution of honey in tap water.

\section{Structural studies}

The micromorphology of the leaflet surfaces in $P$. sativum was studied using scanning electron microscopy (SEM). Leaflets, cut off of the proximal part of the compound leaf using a razor blade, were air dried, glued with polyvinyl alcohol Tissue-Teck ${ }^{\circledR}$ O.C.T. ${ }^{\text {TM }}$ Compound (Sakura Finetek Europe B.V., Zoeterwoude, The Netherlands) to holders, sputter-coated with gold-palladium (3-6 nm) and examined in a SEM Hitachi S-4800 (Hitachi High-Technologies Corporation, Tokyo, Japan) at $3 \mathrm{kV}$ accelerating voltage. Samples were observed either intact or after treatment with chloroform for $20 \mathrm{~s}$ at $60^{\circ} \mathrm{C}$. Type of wax projections was identified according to the generally accepted classification of plant epicuticular waxes 
(Barthlott et al. 1998). Wax crystal dimensions and density were quantified from digital images using SigmaScan Pro 5 software (SPSS Inc., Chicago, USA).

To study attachment devices in $C$. montrouzieri, beetles were air-dried, mounted dorsally on holders, sputter-coated with gold-palladium (3-6 nm) and examined in the SEM at $3 \mathrm{kV}$.

Contact angle measurements and estimation of the free surface energy

The free surface energy and its dispersion and polar components were estimated by applying a high-speed optical contact angle measuring device OCAH 200 (DataPhysics Instruments $\mathrm{GmbH}$, Filderstadt, Germany; for detailed device description see Maier 2002). To calculate the free surface energy, contact angles of a series of well-characterised liquids (water, density $=1.000 \mathrm{~kg} / \mathrm{m}^{3}$; diiodomethane, dens. $=3.325 \mathrm{~kg} / \mathrm{m}^{3}$; ethylene glycol, dens. $=1.113 \mathrm{~kg} / \mathrm{m}^{3}$ ) were used. Leaflets were cut off of the proximal part of the compound leaf using a razor blade and then attached with a double-sided tape tesa ${ }^{\circledR}$ fotostrip (Tesa AG, Hamburg, Germany) to a glass slide. Static contact angles of liquids on surfaces were evaluated using the sessile drop method (drop volume $2 \mu \mathrm{l}$ ) with circle- or ellipse-fitting. The free surface energy and its components were calculated according to the universal Owens-WendtKaelble method (Owens and Wendt 1969). For both, the waxy and glossy mutants, the free surface energy of the adaxial and abaxial surfaces of 3 leaflets belonging to 3 plants was calculated. For each plant, 4-5 measurements of the contact angle of each liquid on each surface were conducted. Clean flat glass plate was used as a reference surface (1 sample, 5 measurements per liquid). In total, 193 contact angle measurements were performed.

\section{Traction experiments with insects}

Traction experiments with tethered walking beetles C. montrouzieri were carried out to measure insect attachment forces on different surfaces. Force tests were performed with a load cell force transducer (10 g capacity, Biopac Systems Ltd., Santa Barbara, CA, USA; Gorb and Popov 2002). Both males and females were used in experiments. To make experimental insects incapable of flying, elytra were glued together with a small droplet of molten wax prior to experiments. The beetle was attached to the force sensor by means of a hair (10-15 cm long), glued to the dorsal surface of the insect thorax with a droplet of molten wax. Leaflets $(1.5-2.0 \mathrm{~cm}$ in diameter) were cut off of the proximal part of the leaf using a razor blade and then, intact or treated, attached with double-sided adhesive tape to a horizontal glass plate. Five types of substrates were tested: (1) intact adaxial and abaxial leaflet surfaces of the waxy plant, (2) intact adaxial and abaxial leaflet surfaces of the glossy plant, (3) adaxial and abaxial leaflet surfaces of waxy plants, treated with hot $\left(60^{\circ} \mathrm{C}\right)$ chloroform for $20 \mathrm{~s}$, (4) adaxial and abaxial leaflet surfaces of glossy plants, treated with hot chloroform, and (5) a glass plate as a control. With each individual beetle, two force tests were carried out: first on the glass substrate, then on one of the plant surfaces. The force, generated by the insect walking horizontally on test substrates, was measured. Force-time curves, where the beetle stretched the hair for ca. $1 \mathrm{~min}$, were used to estimate the maximal traction force (Gorb et al. 2005). Tests were carried out at the room temperature of $23-25^{\circ} \mathrm{C}$ and $40-45 \%$ of relative humidity. For each plant surface type, experiments with 9 individual insects were conducted. Three leaflets from three plants per surface were used. In all, 72 insects were tested and 144 force measurements were performed.

\section{Results}

\section{Leaflet surface micromorphology}

There is a difference in the crystalline epicuticular wax coverage between the adaxial and abaxial leaflet surfaces in both waxy and glossy plants, and between two mutants (Table 1).

The adaxial leaflet surface in waxy plants bears a network of interconnected numerous membranous platelets, occurring in high density and covering the surface uniformly and completely (Fig. 1a, b). Although crystals vary greatly in size and shape, they are rather small and have predominantly irregular shapes with indented, often fringed outside edges (Table 1). The platelets are connected with the underlying

Table 1 Wax crystal type, dimensions and density on the adaxial $(a d)$ and abaxial $(a b)$ leaflet surfaces in waxy and glossy plants of Pisum sativum

\begin{tabular}{|c|c|c|c|c|c|c|c|c|c|c|}
\hline \multirow[t]{2}{*}{ Surface } & \multirow[t]{2}{*}{$\begin{array}{l}\text { Crystal } \\
\text { type }\end{array}$} & \multicolumn{3}{|c|}{ Length $(\mu \mathrm{m})$} & \multicolumn{3}{|c|}{ Width $(\mu \mathrm{m})$} & \multicolumn{3}{|c|}{$\begin{array}{l}\text { Density } \\
\left(\mu \mathrm{m}^{-2}\right)\end{array}$} \\
\hline & & ave & $S D$ & $n$ & ave & $S D$ & $n$ & ave & $S D$ & $n$ \\
\hline $\begin{array}{c}\text { Waxy } \\
\text { ad }\end{array}$ & Platelets & 1.54 & 0.31 & 100 & 0.80 & 0.27 & 100 & 4.38 & 0.92 & 5 \\
\hline \multirow{3}{*}{$\begin{array}{c}\text { Waxy } \\
\text { ab }\end{array}$} & Ribbons & 2.68 & 0.67 & 50 & 0.49 & 0.16 & 50 & \multirow[t]{3}{*}{1.79} & \multirow{3}{*}{\multicolumn{2}{|c|}{0.315}} \\
\hline & Filaments & 2.19 & 0.65 & 50 & 0.14 & 0.04 & 50 & & & \\
\hline & Rodlets & 2.60 & 1.04 & 40 & 0.61 & 0.22 & 40 & & & \\
\hline $\begin{array}{l}\text { Glossy } \\
\text { ad }\end{array}$ & Platelets & 1.20 & 0.44 & 100 & 0.57 & 0.23 & 100 & 1.84 & 0.74 & 5 \\
\hline \multirow{2}{*}{$\begin{array}{l}\text { Glossy } \\
\text { ab }\end{array}$} & Ribbons & 1.14 & 0.36 & 50 & 0.27 & 0.13 & 50 & \multirow[t]{2}{*}{5.97} & \multirow{2}{*}{\multicolumn{2}{|c|}{$0.90=$}} \\
\hline & Scales & 0.41 & 0.19 & 50 & 0.28 & 0.14 & 50 & & & \\
\hline
\end{tabular}

ave mean value, $n$ sample size, $S D$ standard deviation 
Fig. 1 SEM micrographs of the crystalline epicuticular wax coverage on the adaxial $(\mathbf{a}-\mathbf{d})$ and abaxial (e-h) leaflet surfaces in waxy $(\mathbf{a}, \mathbf{b}, \mathbf{e}, \mathbf{f})$ and glossy plants $(\mathbf{c}, \mathbf{d}, \mathbf{g}, \mathbf{h})$ of Pisum sativum. AP, aggregated platelets; FL, filaments; PL, platelets; $\mathrm{RB}$, ribbons; RD, rodlets; SC, scales

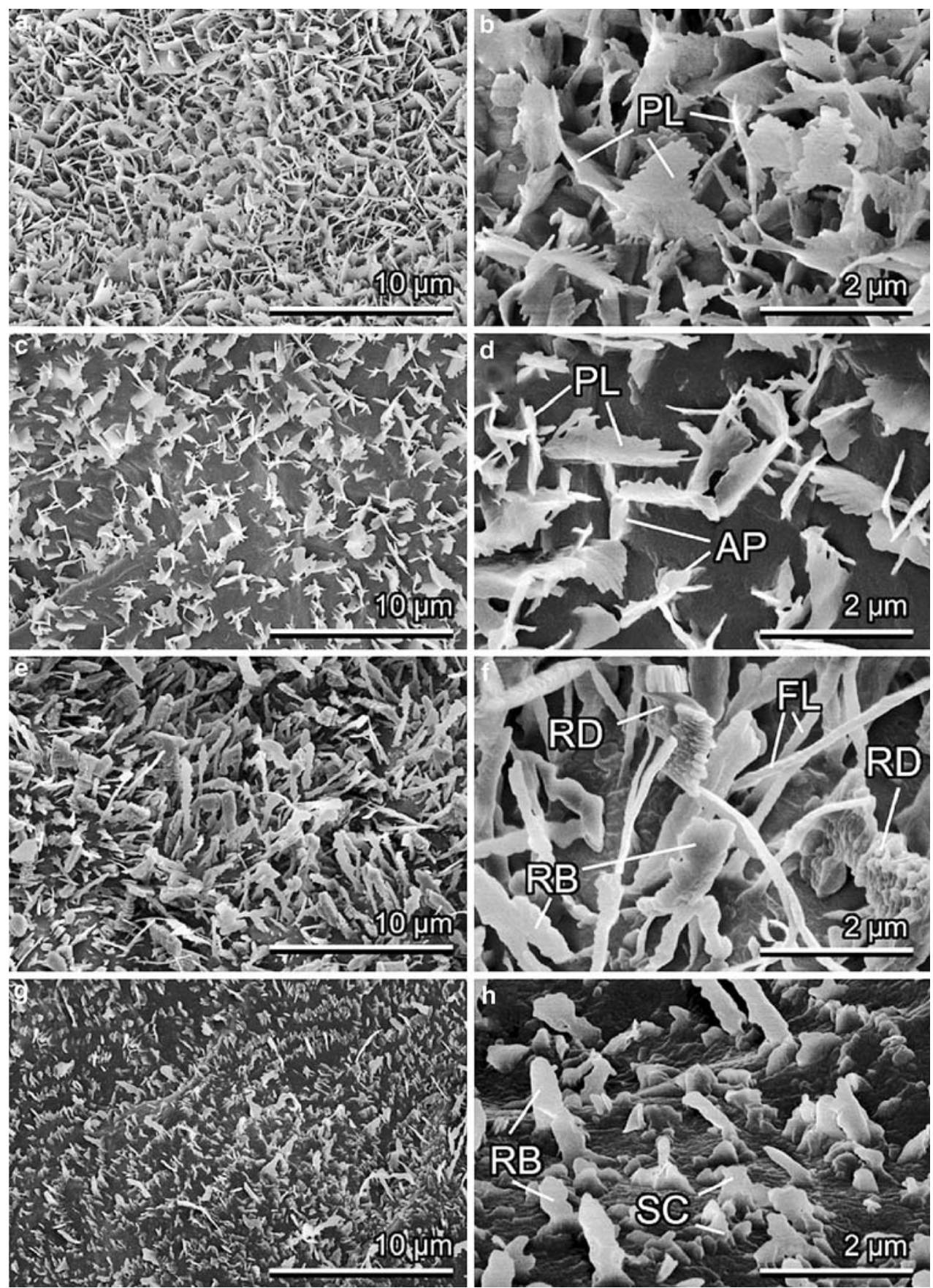

surface through edges. Crystal planes are oriented randomly according to their longitudinal axes, but perpendicular or slightly sloped relatively to the plane of the leaflet.

In glossy plants, the wax coverage present on the adaxial side is similar to the waxy pea. However, wax crystal density on the adaxial surface of the glossy mutant is reduced by a factor of three compared to the waxy plants, and the surface is not completely covered with the crystalline wax (Table 1; Fig. 1c). The membranous platelets have similar shapes as in waxy peas, but are longer and narrower (Fig. 1d). They emerge often as aggregated crystals (rosettes) and are connected with the underlying surface through a larger edge. The crystals show no specific orientation, and their planes are either perpendicular to or more often have acute angles with the leaflet surface.

The abaxial surface of waxy plants is completely covered with the dense crystalline wax coverage, composed of crystals of three types: large elongated filaments, ribbons, and transversely ridged rodlets (Table 1; Fig. 1e). Crystals vary essentially in size and shape, emerge solitarily, are connected with the underlying surface through a small edge, show no preferred orientation and are somewhat 
Fig. 2 SEM micrographs of the adaxial (a-d) and abaxial (e-h) leaflet surfaces in waxy $(\mathbf{a}, \mathbf{b}, \mathbf{e}$, f) and glossy plants $(\mathbf{c}, \mathbf{d}, \mathbf{g}, \mathbf{h})$ of Pisum sativum after treatment with warm chloroform
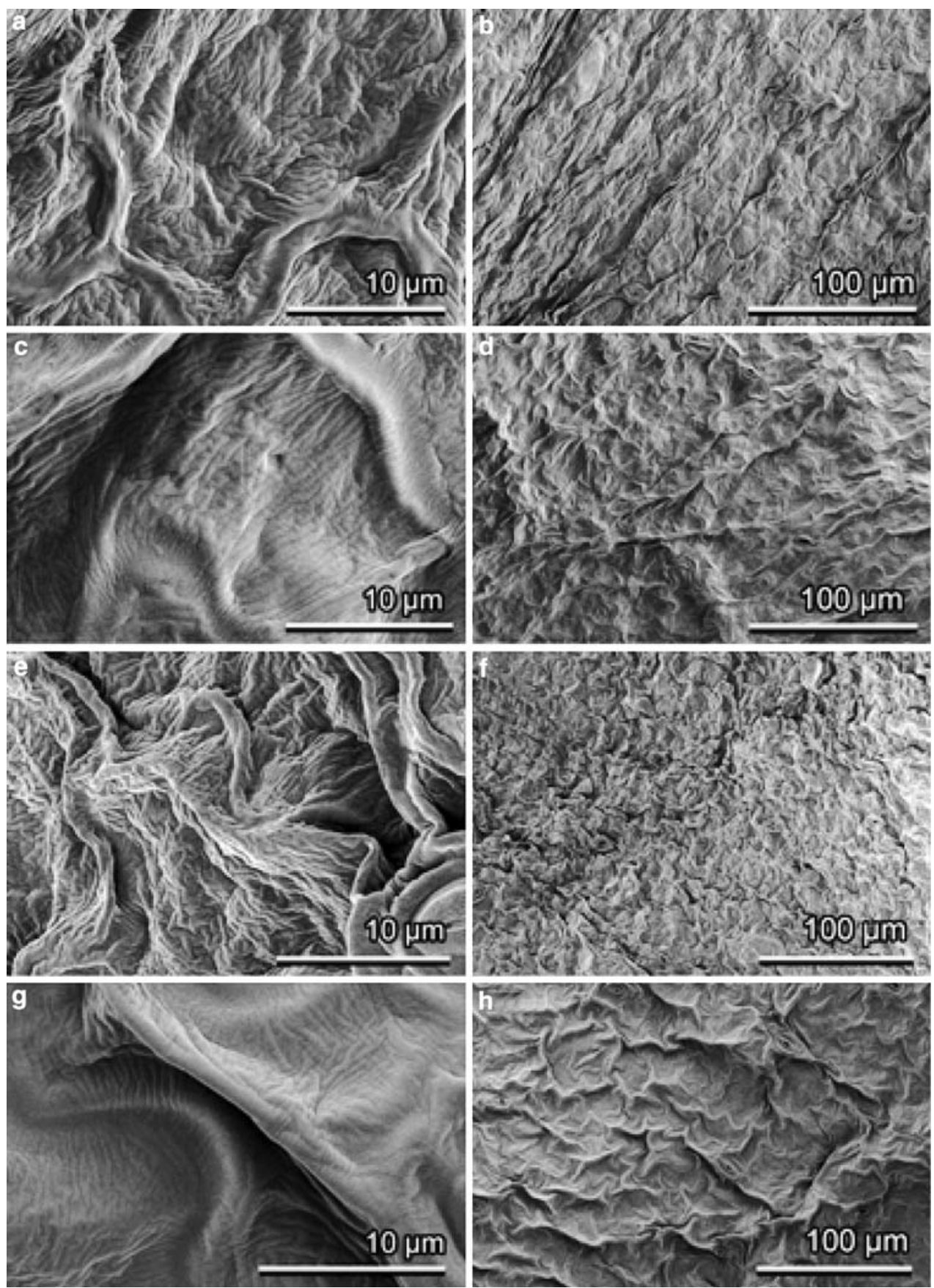

crowded to the surface (Fig. 1f). Ribbons have slightly irregular edges and possess widened, sometimes spatulaelike tips with rather corrugated surface. Rodlets are usually bar- or ribbon-shaped, with very uneven sides and edges.

Although the density of wax crystals on the abaxial side of the glossy mutant is much higher than on all other surfaces studied here, this surface is not completely covered with the crystalline wax (Table 1; Fig. 1g, h). Crystals of two types, short ribbons and scales, are very variable in both size and shape being essentially smaller and having more regular edges than crystals on the abaxial surface of the glossy mutant. As well as latter, these crystals originate solitarily and have random orientation relatively to their longitudinal axes, but are connected with the surface through small (ribbons) or large (scales) sides and may be either erect or crowded to the substrate.

After treatment with warm chloroform, both leaflet sides of both mutants were completely free of wax crystals (Fig. 2a, c, e, g) and therefore, the microroughness was removed. However, treated surfaces became corrugated, with a noticeably increased large-scale roughness (Fig. 2b, $\mathrm{d}, \mathrm{f}, \mathrm{h})$. 
Physicochemical properties of leaflet surfaces

In all plants studied, both adaxial and abaxial leaflet surfaces were unwettable with both polar liquids, such as water (surface tension $=72.1 \mathrm{mN} / \mathrm{m}$, dispersion component $=19.9 \mathrm{mN} / \mathrm{m}$, polar component $=52.2 \mathrm{mN} / \mathrm{m}$, Busscher et al. 1984) and ethylene glycol (surf. tension $=48.0 \mathrm{mN} / \mathrm{m}$, disp. comp. $=29.0 \mathrm{mN} / \mathrm{m}$, pol. comp. $=19.0 \mathrm{mN} / \mathrm{m}$, Erbil 1997) (Fig. 3a). Contact angles of water were the highest compared to other liquids and seemed to be rather similar on all surfaces. However, the statistic difference was found in contact angles of water between plant surfaces studied (Kruskal-Wallis one way ANOVA on ranks, $H_{3,58}=9.728, P=0.021$ ), where the adaxial side of the waxy mutant and the abaxial side of the glossy mutant was the only surface pair with significantly different angles (Dunn's method carried out after KruskalWallis one way ANOVA on ranks, d.f. $=28$, diff. of ranks $=17.367, Q=2.769, P<0.05)$. Contact angles of ethylene glycol were significantly lower in glossy plants compared to waxy ones (one way ANOVA, $F_{3,59}=24.100$, $P<0.001)$. In both waxy and glossy mutants, no significant difference in contact angles of ethylene glycol was detected between the abaxial and adaxial leaflet sides (Table 2). Contact angles of non-polar diiodomethane (surf. tension $=50.0 \mathrm{mN} / \mathrm{m}, \quad$ disp. comp. $=47.4 \mathrm{mN} / \mathrm{m}$, pol. comp. $=2.6 \mathrm{mN} / \mathrm{m}$, Busscher et al. 1984) were lower than those of both water and ethylene glycol. The abaxial surface of glossy plants was wetted with diiodomethane (contact angle $=75.3 \pm 6.4^{\circ}$, mean $\pm \mathrm{SD}, n=15$ drops, $N=3$ plants). The leaflet surfaces studied showed highly significant difference in contact angles of latter liquid (one way ANOVA, $\left.F_{3,58}=111.810, P<0.001\right)$. The abaxial side of the waxy mutant and the adaxial side of the glossy mutant was the only surface pair, where contact angles of diiodomethane did not differ significantly (Table 3 ).

Considering morphometrical parameters of the waxy coverage of the leaflet surfaces (average size and density of wax crystals), there was no significant correlation between contact angles and any morphometrical parameters tested (cont. angle of water versus cryst. length: $R^{2}=0.118$, $P=0.144$; cont. angle of water versus cryst. dens.: $R^{2}=0.526, P=0.144$; cont. angle of ethylene glycol versus cryst. length: $R^{2}=0.488, P<0.001$; cont. angle of ethylene glycol versus cryst. dens.: $R^{2}=0.082$, $P=0.186$; cont. angle of diiodomethane versus cryst. length: $R^{2}=0.121, P=0.011$; cont. angle of diiodomethane versus cryst. dens.: $R^{2}=0.023, P=0.159$ ).

Leaflet surfaces in both plant mutants showed rather low values of the free surface energy with the prevailing dispersion component (Fig. 3b). The lowest surface energy with the highest dispersion component was observed for the adaxial surface of waxy plants, whereas in the abaxial
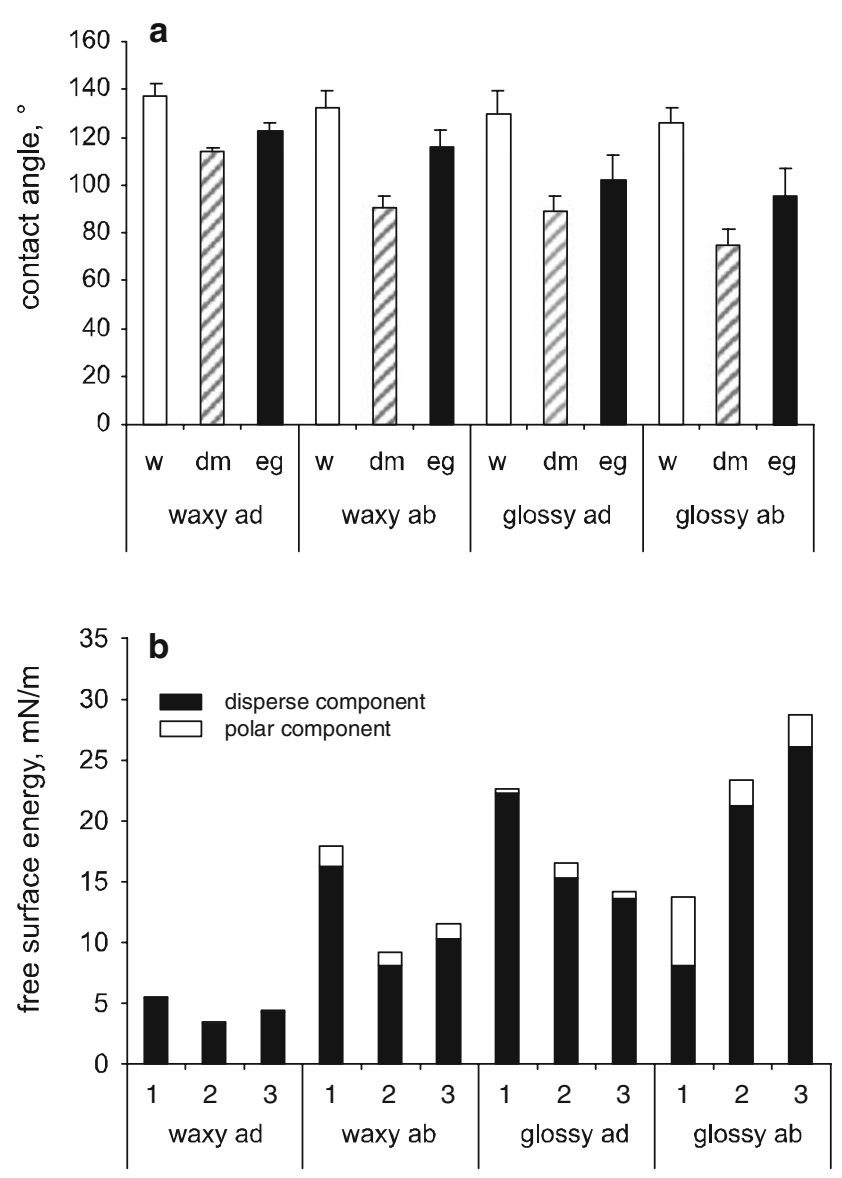

Fig. 3 Contact angles of water, diiodomethane, and ethylene glycol (a) and values of the free surface energy (b) in different leaflet surfaces of Pisum sativum. dm, diiodomethane; eg, ethylene glycol; glossy ab, abaxial surface of the glossy mutant; glossy ad, adaxial surface of the glossy mutant; $w$, water; waxy ab, abaxial surface of the waxy plant; waxy ad, adaxial surface of the waxy plant; $1,2,3$, three different plants. For statistics see Tables 2 and 3

Table 2 Results of pairwise multiple comparisons of means (HolmSidak method) carried out after one way ANOVA for the contact angles of ethylene glycol on adaxial $(a d)$ and abaxial $(a b)$ leaflet surfaces in waxy and glossy plants of Pisum sativum

\begin{tabular}{lllll}
\hline Comparison & \multicolumn{1}{l}{ DM } & $p$ & \multicolumn{1}{l}{$t$} & $P<0.05$ \\
\hline Waxy ad versus glossy ab & 26.680 & 15 & 7.576 & Yes \\
Waxy ad versus glossy ad & 20.347 & 15 & 5.778 & Yes \\
Waxy ab versus glossy ab & 19.927 & 15 & 5.658 & Yes \\
Waxy ab versus glossy ad & 13.593 & 15 & 3.860 & Yes \\
Waxy ad versus waxy ab & 6.753 & 15 & 1.918 & No \\
Glossy ad versus glossy ab & 6.333 & 15 & 1.798 & No
\end{tabular}

$D M$ difference of means, no no significant difference, $p$ number of means spanned in the comparison, $P$ probability value, $t$ test statistics, yes significant difference

leaflet side of the glossy mutant, the surface energy was several times higher with markedly higher polar component. As for the abaxial surface of waxy plants and the 
Table 3 Results of pairwise multiple comparisons of means (HolmSidak method) carried out after one way ANOVA for the contact angles of diiodomethane on adaxial $(a d)$ and abaxial $(a b)$ leaflet surfaces in waxy and glossy plants of Pisum sativum

\begin{tabular}{lrlll}
\hline Comparison & \multicolumn{1}{l}{ DM } & \multicolumn{1}{l}{$t$} & $P<0.05$ \\
\hline Waxy ad versus glossy ab & 38.393 & 15 & 18.069 & Yes \\
Waxy ad versus glossy ad & 24.220 & 15 & 11.398 & Yes \\
Waxy ad versus waxy ab & 23.051 & 15 & 10.660 & Yes \\
Waxy ab versus glossy ab & 15.342 & 15 & 7.095 & Yes \\
Glossy ad versus glossy ab & 14.173 & 15 & 6.670 & Yes \\
Waxy ab versus glossy ad & 1.169 & 15 & 0.540 & No \\
\hline
\end{tabular}

$D M$ difference of means, no no significant difference, $p$ number of means spanned in the comparison, $P$ probability value, $t$ test statistics, yes significant difference

adaxial side in glossy plants, there was no considerable difference besides slightly higher values of the total surface energy in latter surfaces.

Morphology of the beetle attachment system

The tarsus of $C$. montrouzieri consists of three segments (Fig. 4a, e). The distal tarsomere (T3) bears paired claws, curved ventrally, each with a tooth. Attachment pads are of the hairy type (Beutel and Gorb 2001; Gorb 2001). The ventral side of the two first proximal tarsomeres (T1 and T2) is densely covered by tiny tenent setae (Fig. 4b, f). The setae of the first tarsomere $\mathrm{T} 1$ are more or less uniform, with straight or slightly curved pointed tips (Fig. 4c, d). In the second tarsomere $\mathrm{T} 2$, setae of the two types were found: (1) with pointed tips and (2) with flattened and widened tips called spatulae (Fig. 4g, h). No sexual dimorphism in the morphology of the attachment system in C. montrouzieri was detected.

Traction forces of beetles on pea leaflet surfaces

Although the maximal traction force generated on glass by different insect individuals $(0.5-11.8 \mathrm{mN})$ did not vary significantly in different experiments (Kruskal-Wallis one way ANOVA on ranks, $H_{7,71}=9.597, P=0.213$ ), we used data, normalised to values obtained on glass, for comparison of different surfaces. For each individual, the force, obtained on a test plant surface, was compared to that on glass (considered as $100 \%$ ).

For all intact plant surfaces tested, with the only exception of the abaxial side in the glossy mutant, the values of the maximal traction force of beetles differed significantly from those, produced on the glass plate (Kruskal-Wallis one way ANOVA on ranks, $H_{4,44}=27.954, P<0.001$; Table 4; Fig. 5a). The comparison of different intact plant surfaces (one way
ANOVA, $F_{3,35}=4.681, P=0.008$ ) showed that on waxy plants, insects produced similar forces regardless of a leaflet surface, while higher force was measured on the abaxial side in the glossy pea (Table 5). There was no significant difference between adaxial surfaces in waxy and glossy plants, whereas on the abaxial side, the force was stronger in the glossy mutant.

Considering morphometrical parameters of the waxy coverage of the leaflet surfaces (average size and density of wax crystals) and surface wettability (contact angles of water, ethylene glycol and diiodomethane), a significant correlation was found for the traction force with both the wax crystal length and density (Fig. 6). There was no significant correlation between the force and contact angles of any liquid (force versus cont. angle of water: $R^{2}=0.202, P=0.145$; force versus cont. angle of ethylene glycol: $R^{2}=0.544, P=0.014$; force versus cont. angle of diiodomethane: $R^{2}=0.376, P=0.043$ ).

Treatment of plant surfaces with chloroform resulted in a substantial increase of traction forces on both leaflet sides in both waxy and glossy plants, compared to those on intact surfaces (Table 6; Fig. 5). Compared with glass (KruskalWallis one way ANOVA on ranks, $H_{4,44}=12.283$, $P=0.015$; Fig. 5b), the abaxial leaflet side of the waxy pea was the only substrate, where the force was significantly higher (Tukey test carried out after Kruskal-Wallis one way ANOVA on ranks, d.f. $=17$, diff. on ranks $=168.000, q=4.264, P<0.05$ ), and no difference was found between other treated plant surfaces and glass. The comparison of treated leaflet surfaces showed no statistically significant difference in traction forces of insects between plant substrates tested (one way ANOVA, $\left.F_{3,35}=1.675, P=0.192\right)$.

\section{Discussion}

Ultrastructure and properties of the wax coverage

It is established that the wax structure can differ between the leaf surfaces of the same plant individual (Juniper 1959; Juniper and Cox 1973). For P. sativum, it has been previously repeatedly reported that both leaflet surfaces are densely covered with crystalline epicuticular waxes having markedly divergent micro-morphology and chemical composition: alcohol-rich plates/platelets on the adaxial surface and alkane-rich ribbons or filaments on the abaxial side (Halloway et al. 1977; Hunt and Baker 1982; Gniwotta et al. 2005; Jeffree 2006). Additionaly, few cylindrical rodlets (cultivars Avanta and Lincoln) and short crystals with different shapes of cross sections and flat upper surface (cultivar Maiperle) have been found on the abaxial surfaces (Gniwotta et al. 2005). Our SEM study of this 
Fig. 4 Attachment system of the beetle Cryptolaemus montrouzieri (female, SEM). (a) Lateral and (e) ventral view of the tarsus. (b-d) The first proximal tarsomere. $(\mathbf{f}-\mathbf{h})$ The second proximal tarsomere. CL, claws; PS, setae with pointed tips; SS, setae with flattened and widened tips, spatulae; T1-T3, tarsomeres 1-3. Arrows show distal direction
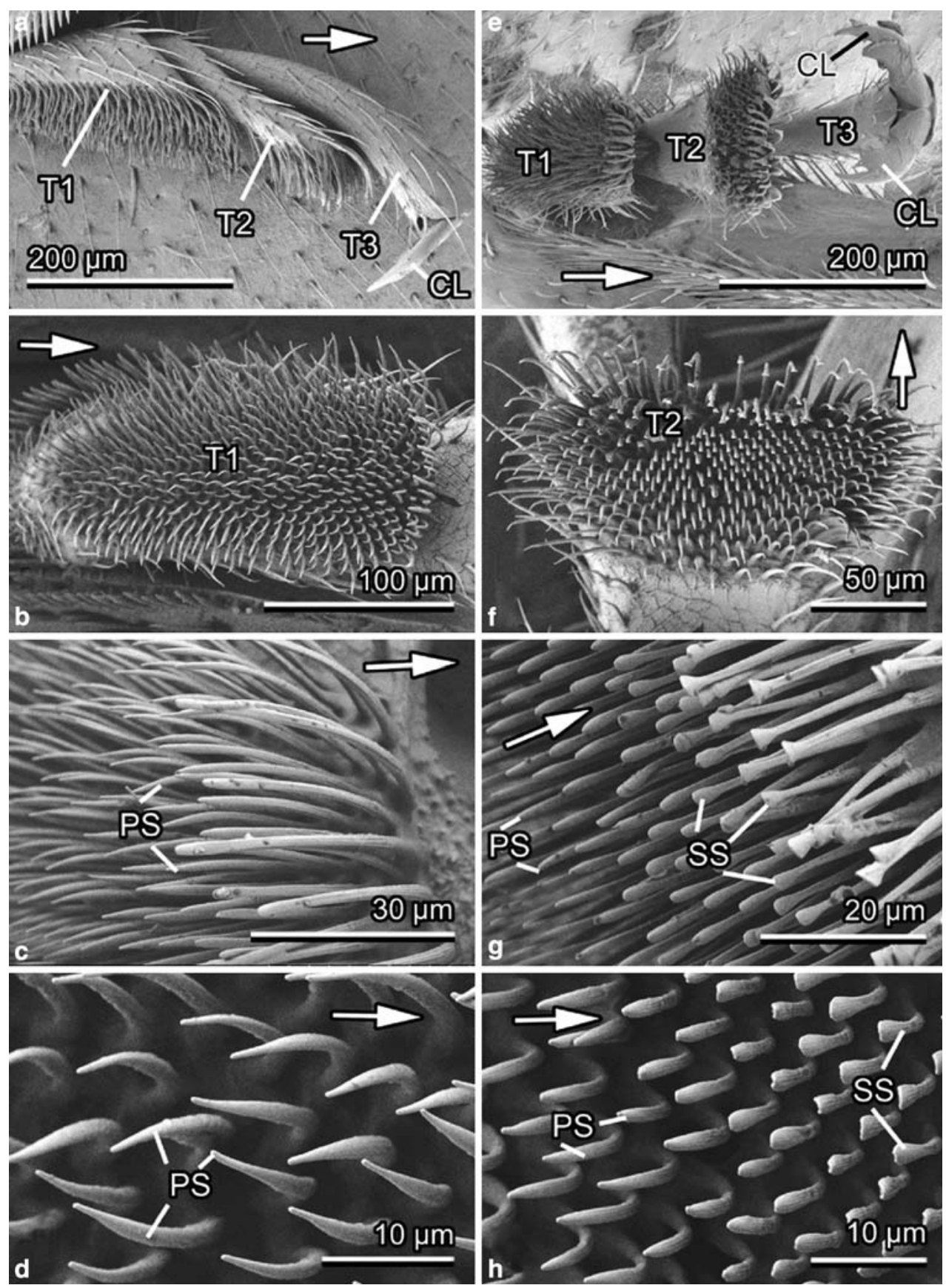

leaflet surface in the waxy plants reveals the presence of both ribbons and rather large amount of filaments, which were not absolutely upright, as it has been reported previously, but somewhat crowded to the surface. Transversely ridged rodlets were found for the first time for this leaflet side.

In low-wax pea plants, wel mutation (wax eliminator) has been previously described to be unique among wax mutations in peas, since it reduced strongly the wax bloom on all aerial plant surfaces (Marx 1969). Glossy plants had shinier, darker green leaves (White and Eigenbrode 2000a), significantly lower (up to approximately 80\%) wax load
(Eigenbrode et al. 1997, 2008; White and Eigenbrode 2000a, b; Rutledge and Eigenbrode 2003), decreased amount of large crystals (Eigenbrode et al. 1997; 1998; White and Eigenbrode 2000a, 2000b) and higher density of minute crystals on both leaf sides (Eigenbrode et al. 1997, 1998). No ribbons, but only $1 \mu \mathrm{m}$ needles and granules were found on the abaxial surface (Eigenbrode et al. 1997). Wax in glossy plants was less extractable (White and Eigenbrode 2000a) and showed changed composition with decreased proportions of alcohols and alkanes (Eigenbrode et al. 1997, 1998). This literature contains some contradictions regarding the crystal density and wax micro-structure 
Table 4 Results of pairwise multiple comparisons of means (Tukey test) carried out after Kruskal-Wallis one way ANOVA on ranks for the maximal traction forces, produced by beetles Cryptolaemus montrouzieri on glass and intact adaxial $(a d)$ and abaxial $(a b)$ leaflet surfaces in waxy and glossy plants of Pisum sativum

\begin{tabular}{lllll}
\hline Comparison & DR & $p$ & $q$ & $P<0.05$ \\
\hline Glass versus waxy ab & 276.000 & 9 & 5.898 & Yes \\
Glass versus waxy ad & 234.000 & 9 & 4.958 & Yes \\
Glass versus glossy ad & 233.000 & 9 & 4.937 & Yes \\
Glass versus glossy ab & 134.000 & 9 & 2.839 & No \\
\hline
\end{tabular}

$D R$ difference of ranks, no no significant difference, $p$ number of means spanned in the comparison, $P$ probability value, $q$ test statistics, yes significant difference

of the wel mutation: reduced density of small crystals has been reported for the abaxial surface (Eigenbrode et al. 1998). Glossy plants (wel) have been described as possessing amorphous wax in one study (Rutledge and Eigenbrode 2003). Our study showed the presence of crystalline waxes on both leaflet sides in the glossy mutant. We also found that micro-structure of the wax coverage in the adaxial surface did not differ very much between waxy and glossy plants. Rather, in the glossy mutant, crystals were of the same type (platelets), slightly smaller and much more sparsely distributed compared to those of the waxy pea. In contrast, we observed considerable difference between waxy and glossy mutants in the wax coverage of the abaxial leaflet side. No large crystals, but only short ribbons and rather small scales occurred in a great number on the abaxial surface of glossy plants (see Table 1). The reduction in wax crystals we detected on the glossy mutant line 406G (wel homozygote) is not as severe as described
Table 5 Results of pairwise multiple comparisons of means (HolmSidak method) carried out after one way ANOVA for the maximal traction forces, produced by beetles Cryptolaemus montrouzieri on different intact surfaces of Pisum sativum: the adaxial $(a d)$ and abaxial $(a b)$ leaflet surfaces in waxy and glossy plants

\begin{tabular}{lllll}
\hline Comparison & \multicolumn{1}{l}{ DM } & $p$ & \multicolumn{1}{l}{$t$} & $P<0.05$ \\
\hline Glossy ab versus waxy ab & 27.001 & 9 & 3.504 & Yes \\
Glossy ab versus glossy ad & 20.593 & 9 & 2.672 & Yes \\
Waxy ad versus waxy ab & 6.109 & 9 & 0.793 & No \\
Glossy ad versus waxy ad & 0.300 & 9 & 0.039 & No \\
\hline
\end{tabular}

$D M$ difference of means, no no significant difference, $p$ number of means spanned in the comparison, $P$ probability value, $t$ test statistics, yes significant difference

previously for this line (Eigenbrode et al. 1997, 1998). The seed stock used for our study was identical with that used in the prior work, and the growing conditions were similar. The slightly younger stage tested here (3-4 node) versus the older plants used in the prior studies, or an undetermined environmental factor, could account for this apparent discrepancy.

Although superhydrophobic properties of plant surfaces covered with the crystalline wax have been described previously (e.g., Holloway 1969; Juniper and Cox 1973), the contact angle of water on pea leaf surface was measured only recently (Gniwotta et al. 2005). It was found that in three cultivars of $P$. sativum, contact angles were similar $\left(144.7^{\circ} \pm 4.9^{\circ}\right.$ for the adaxial side and $141.2^{\circ} \pm 4.3^{\circ}$ for the abaxial side, mean $\pm \mathrm{SD}$ ), since the epicuticular waxes of these cultivars caused similar roughness and polarity of surfaces. The free surface energy of leaflet surfaces of $P$. sativum was estimated in this study for the first time by
Fig. 5 Maximal traction force, generated by beetles Cryptolaemus montrouzieri (males and females pooled together) on glass compared to intact (a) and treated (b) leaflet surfaces of Pisum sativum (normalised data, i.e. in comparison to measurements on glass). abs, abaxial surface; ads, adaxial surface. Different letters show significant differences between traction force values on different substrates (for statistics see text and Tables 4 and 5)
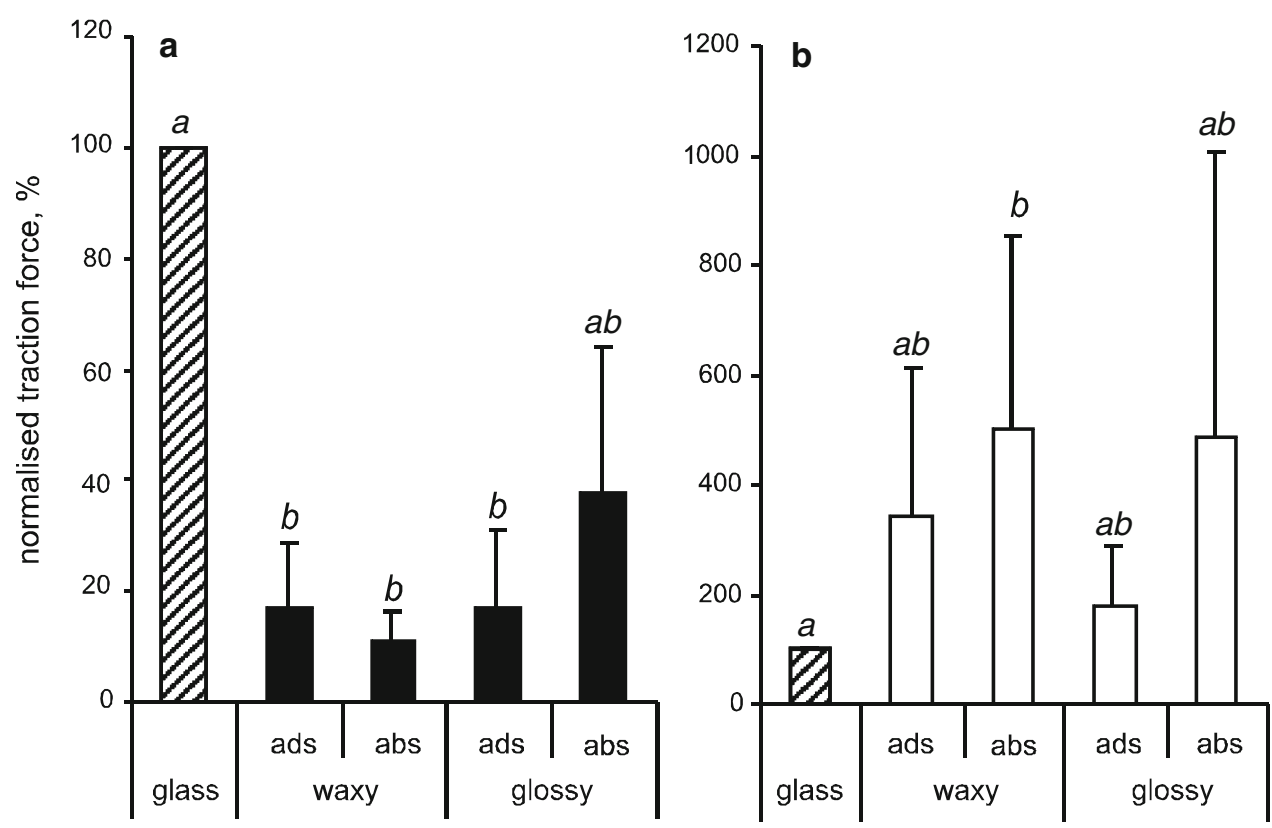


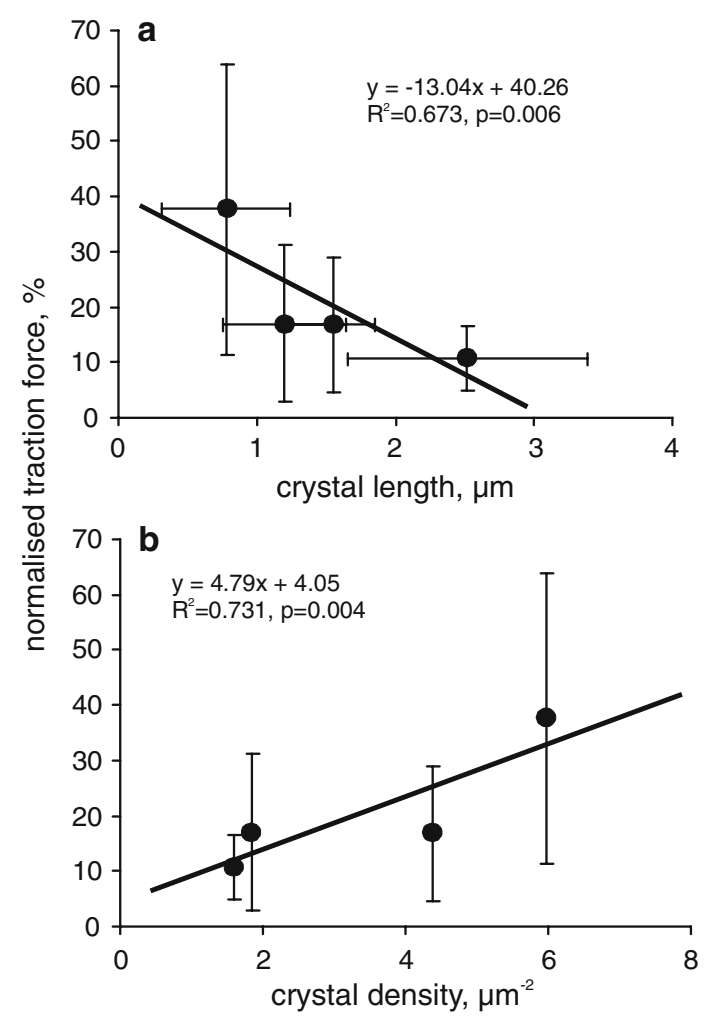

Fig. 6 The maximal traction force, generated by beetles Cryptolaemus montrouzieri on leaflet surfaces of Pisum sativum versus the wax crystal length (a) and density (b). Lines indicate linear regressions

the use of three different liquids. Waxy pea plants were found to have slightly higher contact angles of water than glossy plants, but these angles did not significantly differ between the adaxial and abaxial sides. Glossy plants (especially their abaxial side) were wetted somewhat more strongly by all three liquids tested than were waxy plants.

Although the wax crystal size and density in glossy mutants differ from those in waxy plants, there was no correlation between these two morphometrical parameters of the crystalline wax coverage and contact angles of liquids used. This means that within the range found on these plants, differences in the wax coverage morphology did not explain differences in surface wettability.

Wax-mediated beetle attachment

A great number of insects have evolved specialised adhesive devices, smooth flexible pads or hairy structures, in order to attach to smooth substrates (Gorb 2001; Beutel and Gorb 2001). Compliant pad material in the first case and fibrillar surface structures in the second one ensure sufficiently large contact area between pads and substrate and by this, a high attachment force. Excellent attachment ability on various smooth artificial and natural surfaces has been previously reported for many insects (Way and Murdie 1965; Stork 1980; Edwards 1982; Eigenbrode 1996; Eigenbrode et al. 1999; Federle et al. 2000; Gorb 2001; Gorb and Gorb 2002, 2006a). In waxy plant substrates, the deteriorative effect of the crystalline wax coverage on insect attachment has been experimentally shown by many authors (Stork 1980, 1986; Edwards 1982; Bodnaryk 1992; Eigenbrode 1996; Eigenbrode and Kabalo 1999; Eigenbrode et al. 2000; Federle et al. 2000; Eigenbrode and Jetter 2002; Gaume et al. 2002, 2004; Gorb and Gorb 2002; Gorb et al. 2005; Voigt et al. 2007). It has been found for several insect species and a series of plant species that insects can attach well to smooth substrates, without wax or with removed wax bloom, whereas they fail on waxy surfaces.

Although there is a lot of information on attachment of different insects to $P$. sativum in the literature, the attachment force was measured only in a very few studies (Eigenbrode et al. 1998, 2008; Rutledge and Eigenbrode 2003). Different techniques for force measurement were used, and results reported are rather variable in terms of force values. Force tests on the abaxial surface of waxy $(\mathrm{Wel})$ and glossy (wel) plants with coccinellid predatory beetles Hippodamia convergens Guerin-Menéville, performed by using a force tenaxometer, have shown that adhesion was $>30$-fold stronger in the glossy pea

Table 6 Results of pairwise multiple comparisons of means (Tukey test) carried out after Kruskal-Wallis one way ANOVA on ranks for the maximal traction forces, produced by beetles Cryptolaemus montrouzieri on intact (int) and treated with chloroform (tr) leaflet surfaces of Pisum sativum: the adaxial $(a d)$ and abaxial $(a b)$ surfaces in waxy and glossy plants

\begin{tabular}{lccc}
\hline Comparison & DR & $p$ & $q$ \\
\hline Kruskal-Wallis one way ANOVA on ranks $H_{3,35}=26.560, P<0.001$ & & \\
tr Waxy ab versus int waxy ab & 179.000 & 9 & 5.663 \\
tr Waxy ad versus int waxy ad & 145.000 & 9 & 3.244 \\
Kruskal-Wallis one way ANOVA on ranks $H_{3,35}=25.675, P<0.001$ & & Yes \\
tr Glossy ad versus int glossy ad & 167.000 & 9 & 5.284 \\
tr Glossy ab versus int glossy ab & 141.000 & 9 & Yes \\
\hline
\end{tabular}

$D R$ difference of ranks, $H$ test (Kruskal-Wallis one way ANOVA on ranks) statistics, $p$ number of means spanned in the comparison, $P$ probability value, $q$ Tukey test statistics, yes significant difference 
$(6.448 \mathrm{mN})$ than in the waxy one $(0.197 \mathrm{mN})$ (Eigenbrode et al. 1998). Centrifugal experiments with the same insect species and both leaf surfaces of the same plant mutants have revealed significant, but only up to 2-fold, enhancement of attachment force on glossy plants $(0.182 \pm 0.026 \mu \mathrm{N}$, mean $\pm \mathrm{SD})$ compared with waxy ones $(0.109 \pm 0.017 \mu \mathrm{N}$, mean $\pm \mathrm{SD})$, and no difference between leaf sides has been detected (Rutledge and Eigenbrode 2003). Tests with adults of five coccinellid beetle species (H. convergens, Coccinella transversoguttata Fald., C. septempunctata L., Adalia bipunctata L., and Harmonia axyridis Pallas) on the adaxial side in the same pea mutants by applying of the centrifuge method have shown that each insect species achieved lower attachment forces on waxy peas than on glossy plants (Eigenbrode et al. 2008). Depending on the beetle species, the force was $5-15 \mathrm{mN}$ and $<5 \mathrm{mN}$, respectively.

Our results of traction experiments with $C$. montrouzieri showed that the attachment force (in range of several $\mathrm{mN}$ ) was significantly lower on all pea surfaces studied than that on smooth glass. The only exception was the abaxial leaflet side of the glossy mutant, which permitted significantly higher attachment force than the other plant surfaces. We found that the crystal wax length correlated with beetle attachment force. Additionally, there was a significant correlation between the force and crystal density. Both these morphometrical parameters of the crystalline wax coverage contribute to the surface roughness. The influence of the surface roughness on insect attachment has been tested experimentally only in a few previous studies (Gorb 2001; Peressadko and Gorb 2004; Gorb and Gorb 2006a; Voigt et al. 2008). It has been found that attachment forces were much higher on smooth and rough surfaces compared to micro-rough samples (0.3 and $1.0 \mu \mathrm{m}$ asperity size), since spatula-like terminal elements of tarsal setae of the tested insects are able to generate sufficient contact with smooth substrates or smooth islands within rough substrates. In the present study, a considerable decrease of the wax crystal length (on the abaxial side of glossy plants) led to the reduction of the surface roughness amplitude, and this evidently caused an increase of the traction force (Fig. 7).

IOn the other hand, our results may be also explained by wax crystals contaminating the tarsi of the insects (Stork 1980; Eigenbrode et al. 1996; Gorb and Gorb 2002, 2006c; Gorb et al. 2005). Although we have not examined pads for contamination here, it has been previously demonstrated for a series of plant species that crystals with high aspect ratio are more breakable and have a considerably stronger ability to contaminate insect adhesive pads and hinder essentially the adhesion (Gorb et al. 2005; Gorb and Gorb 2006c).

Physicochemical properties of plant surfaces (wettability by water and the free surface energy) in terms of their influence on insect attachment have been recently

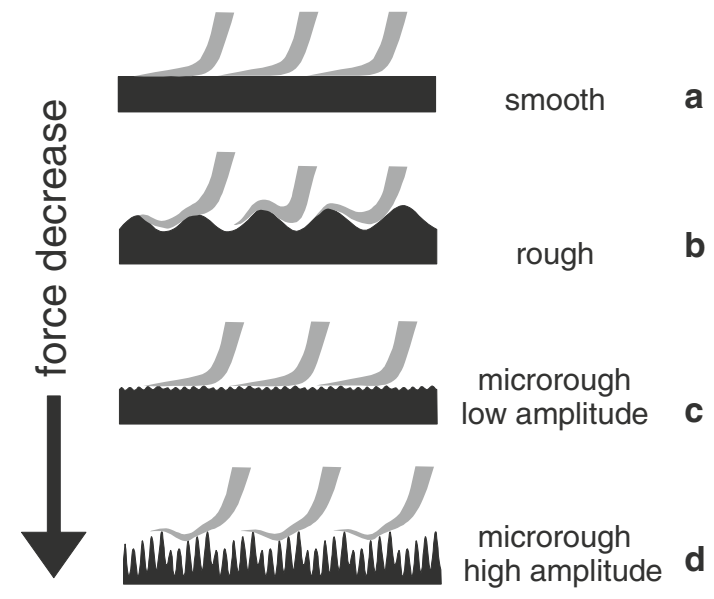

Fig. 7 Diagram explaining results obtained in traction tests. Since force, generated by insects, depends on the real contact area between setal tips of their adhesive organs and substrate, the substrate geometry is a crucial parameter influencing insect attachment. a On the smooth substrate (glass), setal tips have the maximum contact and therefore, maximal attachment force. b On the rough substrates, where dimensions of asperities are comparable with the size of setal tips, the real contact area is slightly reduced; however, tips can adjust to the substrate profile. c When dimensions of asperities are much smaller than the size of setal tips, the real contact area is strongly reduced, because terminal elements of setae can not adjust to the minute asperities. $\mathbf{d}$ In the case of small dimensions of the asperities and their large amplitude (the case similar to long wax crystals of the pea plant), the real contact area is even more strongly reduced, which results in the strongest decrease of the attachment force. The cases $\mathbf{a}, \mathbf{b}$ and $\mathbf{c}$ were experimentally proven in the previous studies (Gorb 2001; Peressadko and Gorb 2004; Gorb and Gorb 2006a; Voigt et al. 2008). The cases $\mathbf{a}, \mathbf{c}$ and $\mathbf{d}$ correspond to the present study

discussed in some studies (Riedel et al. 2003; Bohn and Federle 2004; Gorb et al. 2004; Gorb and Gorb 2006a, b). It has been reported that hydrophobic substrates reduced adhesion (Riedel et al. 2003; Gorb et al. 2004; Gorb and Gorb 2006a, b). However, we found here no significant correlation between the traction force of $C$. montrouzieri and contact angles of liquids on $P$. sativum leaflet surfaces.

The correlation analyses (Fig. 6) demonstrated dependence of traction forces on the crystal length and density. Crystals of different length and different crystal densities did not strongly affect the surface wettability, but significantly influenced insect attachment. This means that the surface roughness affects the force reduction not necessarily through the wettability reduction, especially if we take into account purely lipide-like nature of a beetle pad secretion (Ishii 1987; Kosaki and Yamaoka 1996; Eisner and Aneshansley 2000). It is clear that here we deal with a complex contact mechanics phenomenon and observe an integration of overlaying effects of various parameters, but data obtained let us assume that the attachment force depends primarily on the surface profile and ability of insects to establish real contact with the substrate and secondarily on the surface wettability. 
Interestingly, the comparison of abaxial and adaxial leaflet surfaces showed comparable force values in waxy plants, whereas a strong difference between these surfaces was found in glossy plants. Thus, based on our data, we can conclude that not only the presence of the crystalline wax, but its morphology influences insect attachment force.

As for the plant substrates, treated with chloroform, removing the wax from the surface, we obtained much higher forces (of several dozens $\mathrm{mN}$ ) than on a glass, independently of the leaflet side and plant mutant. This effect can be explained by removal of the microroughness caused by wax crystals and probably by a strongly increased surface roughness, enabling beetles to use their claws for mechanical interlocking with the surface (Dai et al. 2002; Gorb et al. 2005; Voigt et al. 2007). In addition, surfaces with large roughness provide enough smooth sites for proper contact formation by single spatulae of adhesive hairs.

\section{Conclusions}

Our data on the ultrastructure and physicochemical properties of the adaxial and abaxial leaflet surfaces in waxy and glossy plants of $P$. sativum and the experimental results obtained in traction tests with beetles $C$. montrouzieri show that insect attachment does not depend solely on plant genetic background.

The epicuticular crystalline wax was not completely eliminated in the glossy mutant: it was only slightly reduced on the adaxial side and underwent greater changes on the abaxial side. We demonstrated here that the difference in the crystal length and density of the wax coverage (within the range found on these plants) did not influence wettability of surfaces, but affected insect attachment.

Acknowledgements Sincere thanks to V. Kastner (MPI for Developmental Biology, Tübingen, Germany) for assistance with traction tests. This work was partly supported by Landesstiftung BadenWürttemberg, Germany (Project "Plants as Source for Biomimetics of Anti-Adhesive Surfaces").

Open Access This article is distributed under the terms of the Creative Commons Attribution Noncommercial License which permits any noncommercial use, distribution, and reproduction in any medium, provided the original author(s) and source are credited.

\section{References}

Aichele D, Schwegler HW (2000) Die Bluetenpflanzen Mitteleuropas. Bd. 2. Franckh-Kosmos Verlags, Stuttgart, 544 pp

Bargel H, Koch K, Cerman Z, Neinhuis C (2006) Structure-function relationship of the plant cuticle and cuticular waxes - a smart material? Funct Plant Biol 33:893-910. doi:10.1071/FP06139

Barthlott W (1990) Scanning electron microscopy of the epidermal surfaces in plants. In: Claugher D (ed) Scanning electron microscopy in taxonomy and functional morphology. Clarendon Press, Oxford, pp 69-94

Barthlott W, Neinhuis C, Cutler D, Ditsch F, Meusel I, Theisen I, Wilhelmi H (1998) Classification and terminology of plant epicuticular waxes. Bot J Linn Soc 126:237-260

Beutel R, Gorb SN (2001) Ultrastructure of attachment specialization of hexapods (Arthropoda): evolutionary patterns inferred from a revised ordinal phylogeny. J Zool Syst Evol Res 39:177-207. doi:10.1046/j.1439-0469.2001.00155.x

Bodnaryk RP (1992) Leaf epicuticular wax, an antixenotic factor in Brassicaceae that affects the rate and pattern of feeding in flea beetles, Phyllotreta cruciferae (Goeze). Can J Plant Sci 72: 1295-1303

Bohn HF, Federle W (2004) Insect aquaplaning: Nepenthes pitcher plants capture prey with the peristome, a fully wettable waterlubricated anisotropic surface. Proc Natl Acad Sci USA 101:14138-14143. doi:10.1073/pnas.0405885101

Booth RG, Pope RD (1986) A review of the genus Cryptolaemus (Coleoptera: Coccinellidae) with particular reference to the species resembling C. montrouzieri Mulsant. Bull Entomol Res 76:701-717

Busscher HJ, Vanpert AWJ, Deboer P, Arends J (1984) The effect of the surface roughening of polymers on measured contact angle of liquids. Coll Surf 9:319-331. doi:10.1016/0166-6622(84)80 $175-4$

Cooper MR, Johnson AW (1998) Poisonous plants and fungi in Britain: Animal and human poisoning. The Stationery Office, London, $398 \mathrm{pp}$

Dai Z, Gorb S, Schwarz U (2002) Roughness-dependent friction force of the tarsal claw system in the beetle Pachnoda marginata (Coleotera, Scarabaeidae). J Exp Biol 205:2479-2488

Edwards PB (1982) Do waxes of juvenile Eucalyptus leaves provide protection from grazing insects? Aust J Ecol 7:347-352. doi: 10.1111/j.1442-9993.1982.tb01309.x

Eigenbrode SD (1996) Plant surface waxes and insect behaviour. In: Kerstiens G (ed) Plant cuticles - an integral functional approach. BIOS, Oxford, pp 201-222

Eigenbrode SD, Jetter R (2002) Attachment to plant surfaces by insect predators. Integr Comp Biol 42:1091-1099. doi:10.1093/icb/42. 6.1091

Eigenbrode SD, Kabalo NN (1999) Effects of Brassica oleracea waxblooms on predation and attachment by Hippodomia convergens. Entomol Exp Appl 91:125-130. doi:10.1023/A:100 3613710304

Eigenbrode SD, Castagnola T, Roux M-B, Steljes L (1996) Mobility of three generalist predators is greater on cabbage with glossy leaf wax than on cabbage with a wax bloom. Entomol Exp Appl 81:335-343. doi:10.1007/BF00187043

Eigenbrode SD, White C, Rohde M, Simon CJ (1997) Epicuticular wax phenotype of wel mutation and its effect on pea aphid populations in the greenhouse and in the field. Pisum Genet 29:13-17

Eigenbrode SD, White C, Rohde M, Simon CJ (1998) Behavior and effectiveness of adult Hippodamia convergens (Coleoptera: Coccinellidae) as a predator of Acyrthsiphon pisum (Homoptera: Aphididae) on a wax mutant of Pisum sativum. Environ Entomol 91:902-909

Eigenbrode SD, Kabalo NN, Stoner KA (1999) Predation, behavior, and attachment by Chrysoperla plorabunda larvae on Brassica oleracea with different surface waxblooms. Entomol Exp Appl 90:225-235. doi:10.1023/A:1026416831201

Eigenbrode SD, Rayor L, Chow J, Latty P (2000) Effects of wax bloom variation in Brassica oleracea on foraging by a vespid wasp. Entomol Exp Appl 97:161-166. doi:10.1023/A:1004051 823556

Eigenbrode SD, Snyder WE, Clevenger G, Ding H, Gorb S (2008) Variable attachment to plant surface waxes by predatory insects. 
In: Gorb SN (ed) Functional surfaces in biology. Springer-Verlag (in press)

Eisner T, Aneshansley DJ (2000) Defence by foot adhesion in a beetle (Hemisphaerota cyanea). Proc Natl Acad Sci USA 97:65686573. doi:10.1073/pnas.97.12.6568

Erbil HY (1997) Surface tension of polymers. In: Birdi KS (ed) CRC Handbook of surfaces and colloid chemistry. CRC Press Inc., Boca Raton, pp 265-312

Federle W, Rohrseitz K, Hölldobler B (2000) Attachment forces of ants measured with a centrifuge: better "wax-runners" have a poorer attachment to a smooth surface. J Exp Biol 203:505-512

Gaume L, Gorb S, Rowe N (2002) Function of epidermal surfaces in the trapping efficiency of Nepenthes alata pitchers. New Phytol 156:479-489. doi:10.1046/j.1469-8137.2002.00530.x

Gaume L, Perret P, Gorb E, Gorb S, Labat J-J, Rowe N (2004) How do plant waxes cause flies to slide? Experimental tests of waxbased trapping mechanisms in the three pitfall carnivorous plants. Arthropod Struct Dev 33:103-111. doi:10.1016/j.asd. 2003.11.005

Gniwotta F, Vogg G, Gartmann V, Carver TLW, Riederer M, Jetter R (2005) What do microbes encounter at the plant surface? Chemical composition of pea leaf cuticular waxes. Plant Physiol 139:519-530. doi:10.1104/pp.104.053579

Gorb SN (2001) Attachment devices of insect cuticle. Kluwer Academic Publishers, Dordrecht, $305 \mathrm{pp}$

Gorb EV, Gorb SN (2002) Attachment ability of the beetle Chrysolina fastuosa on various plant surfaces. Entomol Exp Appl 105:13-28. doi:10.1023/A:1021777517981

Gorb E, Gorb S (2006a) Combination of the surface profile and chemistry reduces the attachment of the beetle Gastrophysa viridula on the Rumex obtusifolius leaf surface. In: Salmén L (ed) Proceedings of the 5th plant biomechanics conference, Stockholm, Sweden, August 28-September 1, 2006. Stockholm, vol 2, pp 537-542

Gorb EV, Gorb SN (2006b) Physicochemical properties of functional surfaces in pitchers of the carnivorous plant Nepenthes alata Blanco (Nepenthaceae). Plant Biol 8:841-848. doi:10.1055/ s-2006-923929

Gorb EV, Gorb SN (2006c) Do plant waxes make insect attachment structures dirty? Experimental evidences for the contaminationhypothesis. In: Herrel A, Speck T, Rowe NP (eds) Ecology and biomechanics: a mechanical approach to the ecology of animals and plants. CRC Press Inc., Boca Raton, pp 147-162

Gorb SN, Popov VL (2002) Probabilistic fasteners with parabolic elements: biological system, artificial model and theoretical considerations. Philos Trans R Soc Lond A 360:211-225. doi: 10.1098/rsta.2001.0926

Gorb E, Kastner V, Peressadko A, Arzt E, Gaume L, Rowe N, Gorb S (2004) Structure and properties of the glandular surface in the digestive zone of the pitcher in the carnivorous plant Nepenthes ventrata and its role in insect trapping and retention. J Exp Biol 207:2947-2963. doi:10.1242/jeb.01128

Gorb E, Haas K, Henrich A, Enders S, Barbakadze N, Gorb S (2005) Composite structure of the crystalline epicuticular wax layer of the slippery zone in the pitchers of the carnivorous plant Nepenthes alata and its effect on insect attachment. J Exp Biol 208:4651-4662. doi:10.1242/jeb.01939

Halloway PJ, Hunt GM, Baker EA, Macey MJK (1977) Chemical composition and ultrastructure of the epicuticular wax in four mutants of Pisum sativum (L). Chem Phys Lipids 20:141-155. doi:10.1016/0009-3084(77)90087-1

Holloway PJ (1969) The effects of superficial wax on leaf wettability. Ann Appl Biol 63:145-153. doi:10.1111/j.1744-7348.1969.tb05 475.x

Hunt GM, Baker EA (1982) Developmental and environmental variations in plant epicuticular waxes: some effects on the penetration of naphthylacetic acid. In: Cutler DF, Alvin KL, Price CE (eds) The plant cuticle. Academic Press, London, pp 279-292

Ishii S (1987) Adhesion of a leaf feeding ladybird Epilachna vigintioctomaculata (Coleoptera: Coccinellidae) on a vertically smooth surface. Jap J Appl Entomol Zool 22:222-228

Jeffree CE (2006) The fine structure of the plant cuticle. In: Riederer M, Müller C (eds) Biology of the plant cuticle. Blackwell Publishing Ltd., Oxford, pp 11-125

Juniper BE (1959) Die Oberflächen von Pflanzen. Endeavour 18:20 25. doi:10.1016/0160-9327(59)90112-7

Juniper BE, Cox GC (1973) The anatomy of the leaf surface: the first line of defence. Pestic Sci 4:543-561. doi:10.1002/ps.2780040413

Kosaki A, Yamaoka R (1996) Chemical composition of footprints and cuticula lipids of three species of lady beetles. Jap J Appl Entomol Zool 40:47-53

Kunkel G (1984) Plants for human consumption: an annotated checklist of the edible phanerogams and ferns. Koeltz Scientific Books, Koenigstein, 393 pp

Maier G (2002) Operating manual DataPhysics OCA. Release 2.0. Filderstadt, Germany, $111 \mathrm{pp}$

Marx GA (1969) Two additional genes conditioning wax formation. Pisum Newslett 1:10-11

McGuffin M, Kartesz JT, Leung AY, Tucker AO (2000) Herbs of commerce, 2nd edn. American Herbal Products Association, Silver Spring, USA, p 442

Owens DK, Wendt RC (1969) Estimation of the surface free energy of polymers. J Appl Polym Sci 13:1741-1747. doi: 10.1002/app.1969.070130815

Peressadko AG, Gorb SN (2004) Surface profile and friction force generated by insects. In: Boblan I, Bannasch R (eds) Proceedings of the first international conference Bionik 2004, Hannover, Germany. VDI Verlag, Duesseldorf, pp 257-263

Riedel M, Eichner A, Jetter R (2003) Slippery surfaces of carnivorous plants: composition of epicuticular wax crystals in Nepenthes alata Blanco pitchers. Planta 218:87-97. doi:10.1007/s00425003-1075-7

Rutledge CE, Eigenbrode SD (2003) Epicuticular wax on pea plants decreases instantaneous search rate of Hippodamia convergens larvae and reduces attachment to leaf surfaces. Can Entomol 135:93-101

Stork NE (1980) Role of wax blooms in preventing attachment to brassicas by the mustard beetle, Phaedon cochleariae. Entomol Exp Appl 28:100-107. doi:10.1007/BF00422029

Stork NE (1986) The form of plant waxes: a means preventing insect attachment? In: Juniper BE, Southwood TRE (eds) Insects and the plant surface. Edward Arnold, London, pp 346-347

Voigt D, Gorb E, Gorb S (2007) Plant surface-bug interactions: Dicyphus errans stalking along trichomes. APIS 1:221-243

Voigt D, Schuppert JM, Dattinger S, Gorb SN (2008) Sexual dimorphism in the attachment ability of the Colorado potato beetle Leptinotarsa decemlineata (Coleoptera: Chrysomelidae) to rough substrates. J Insect Physiol 54:765-776. doi:10.1016/ j.jinsphys.2008.02.006

Waines JG (1975) The biosystematics and domestication of peas (Pisum L.). Bull Torrey Bot Club 102:385-395. doi:10.2307/ 2484765

Way MJ, Murdie G (1965) An example of varietal resistance of Brussel sprouts. Ann Appl Biol 56:326-328. doi:10.1111/j.17447348.1965.tb01245.x

White C, Eigenbrode SD (2000a) Effects of surface wax variation in Pisum sativum on herbivorous and entomophagous insects in the field. Environ Entomol 20:773-780

White C, Eigenbrode SD (2000b) Leaf surface waxbloom in Pisum sativum influences predation and intra-guild interactions involving two predator species. Oecologia 124:252-259. doi:10.1007/ s004420000374 